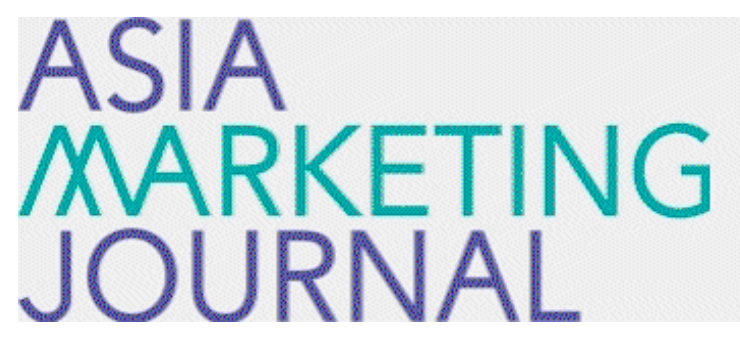

ASIA MARKETING JOURNAL

Volume 7 | Issue 1

Article 1

4-27-2005

\title{
컨버전스 제품에 대한 소비자 평가
}

Hae Ryong Kim

Shin Myung Hong

Moon Kyu Lee

Follow this and additional works at: https://amj.kma.re.kr/journal

Part of the Marketing Commons

\section{Recommended Citation}

Kim, Hae Ryong; Hong, Shin Myung; and Lee, Moon Kyu (2005) "컨버전 스 제품에 대한 소비자 평가," Asia Marketing Journal: Vol. 7 : Iss. 1 , Article 1.

Available at: https://doi.org/10.53728/2765-6500.1135

This Article is brought to you for free and open access by Asia Marketing Journal. It has been accepted for inclusion in Asia Marketing Journal by an authorized editor of Asia Marketing Journal. 


\title{
컨버전스 제품에 대한 소비자 평가
}

\section{Consumer Evaluations of Convergence Products}

\author{
김 해 롱 (Kim, Hae-Ryong) ${ }^{*}$ \\ 홍 신 명 (Hong, Shin-Myung)** \\ 이 문 규(Lee, Moonkyu)***
}

컨버전스 제품들이 기업과 소비자들로부터 관심을 끌고 있는 현실에 비해 이에 대한 학문적인 연 구는 부족한 상황이다. 본 연구는 컨버전스 제품을 구성제품간의 다양한 관계를 바탕으로 한 하이테 크 단일 복합제품으로 정의하였으며. 컨버전스 제품의 어떤 특성들이 소비자들의 태도와 구매의도에 영향을 미칠 수 있는가에 대해 연구를 시도하였다. 이를 위해 기존의 혁신적인 신제품연구와 묶음제 품에 대한 소비자 연구들을 바탕으로 컨버전스 제품관련 혁신특성 변수, 구성특성 변수, 제품 수용자 특성변수를 도출하였으며, 가상의 컨버전스 제품을 대상으로 한 소비자 서베이를 통해 각각의 톡성변 수들의 영향력을 실증적으로 살펴보았다. 연구결과. 컨버전스 제품에 대한 소비자들의 태도와 구매의 도는 컨버전스 제품을 구성하는 각 제품들간의 관계(지각된 일치성, 상대적 이점)에 따라 가장 큰 영 향을 받는 것으로 나타났다. 이 외에도 소비자들이 지각하는 기능적·감성적 위험, 지각된 편리성, 그 리고 해당 소비자의 기술에 대한 성향(테크노그래픽스) 등의 변수들이 컨버전스 제품에 대한 소비자 태도 및 구매의도에 유의적인 영향을 미치는 것으로 나타났다. 이러한 연구결과와 함께 학문적 - 실무 적인 시사점들이 논의된다.

핵심개념: 컨버전스 제품, 혁신저항, 지각된 위험

\section{I. 서 론}

최근 디지털 컨버전스(digital convergence)의 개념과 이를 기초로 한 기술 제품들이 시장에
서 각광을 받고 있다. 디지털 컨버전스는 넓은 의미로 산업과 기술, 그리고 콘텐츠가 융합되는 현상을 말하는데(Hanson 2000), 그 결과 다양 한 컨버전스 제품(convergence product)이 등 장하고 있다. 예를 들어 휴대폰 하나로 전통적

* 건국대학교 사회과학대학 경상학부 조교수(hrkim@kku.ac.kr)

** 연세대학교 대학원(fineday54@yahoo.co.kr)

*** 연세대학교 경영대학 교수(mlee@yonsei.ac.kr) 
인 커뮤니케이션 기능은 물론, 음악 및 TV 방 송, 영화감상과 같은 다양한 멀티미디어 콘텐츠 를 즐길 수 있는 차세대 이동통신 서비스가 나 오고 있다. 이미 히트상품으로 꼽히고 있는, $\mathrm{DVD}$ 와 $\mathrm{VCR}$ 이 결합된 삼성전자의 콤보, 향후 발전될 것으로 보이는 휴대폰 방송, $\mathrm{DMB}$ 서비 스 등도 그 예이다. 또한, 한 제품으로 프린터, 복사기, 스캐너 등의 복합기능을 추구하는 사무 용 기기들의 매출이 과거에 비해 큰 폭으로 증 가하고 있기도 하다(매경이코노미 2002, 2003; 조선일보 2004).

그러나 이러한 컨버전스 제품에 대한 시도가 항상 성공적인 것만은 아니었다. 과거 TV와 $\mathrm{VCR}$ 의 결합이 시도된 적이 있었으나 결과는 실패였다. 최근 들어 인터넷의 열풍과 함께 시 도되었던 인터넷 TV(예: 마이크로소표트의 Web $\mathrm{TV}$ ) 역시 아직까지 성공적 결과를 거두지 못 하고 있다. 이 외에도 많은 컨버전스 제품들이 시장에 출시되었으나 소리 소문도 없이 사라지 기도 하였다. 심지어 한편에서는 기술은 절대로 통합되지 않고 분산된다는 주장도 설득력을 얻 고 있기도 하다(Ries and Ries 1999).

그럽에도 불구하고 기업들의 컨버전스 제품에 대한 관심과 노력은 가속화되고 있으며, 소비자 들의 반응 역시 과거에 비해 뜨거워지고 있는 것이 사실이다. 산업자원부의 최근 발표에 의하 면 2003년 상반기 가전산업의 경우 경기침체에 도 불구하고 디지털 컨버전스 제품을 중심으로 소폭의 내수증가세를 나타냈다고 한다. 최근 들 어 출시되는 휴대폰의 경우 전화만 걸 수 있는 휴대폰은 찾아보기 힘든 실정이다. 심지어 과거 에 출시되어 실패하였던 휴대폰과 PDA 기능을 통합한 스마트폰 역시 새롭게 출시되고 있는
형편이다.

이러한 최근의 경향을 고려해 볼 때, 컨버전 스 제품을 향한 소비자들의 반응에 대한 깊이 있는 이해가 절실하다. 최근 한 보고서에 의하 면 컨버전스 제품이 생각과는 달리 시장을 석권 하지 못하고 있는 이유로 첫째, 기술 - 인프라. 서비스 · 콘텐츠 등의 불균등한 발전으로 제품은 완벽하지만 인프라가 뒷받침되지 않기 때문이 며, 둘째, 특화기기의 빠른 발전을 컨버전스 제 품이 따라가지 못함으로써 발생하는 기능의 열 세 때문이고 마지막으로 소비자들의 소비성향, 즉 제품이 수명을 다했을 때 제품을 구입하거나 조금 더 발전된 제품을 사기 위해 제품구입시기 를 늦추는 성향을 지목하고 있다(나준호 2002).

결국 컨버전스 제품이 시장에서 살아남기 위 해서는 제품의 완성도, 관련 인프라의 구축 및 제품출시의 적절한 타이밍 등 전략적 - 상황적 변수들의 역할 뿐 아니라 기업의 입장에서는 왜 소비자들이 컨버전스 제품에 대한 구매를 주저하고 있는지에 대한 소비자 심리의 이해가 필수적인 셈이다. 본 연구는 이러한 컨버전스 제품의 구매와 관련한 소비자 심리의 이해에 초점을 두고 있다. 그러나 아직까지 컨버전스 제품에 관한 소비자 연구가 매우 미약한 상황 에서 본 연구는 그 출발점을 위해 컨버전스 제 품의 특성과 그에 따른 소비자들의 태도와의 관계에만 초점을 두고 있다. 이를 위해 먼저 컨 버전스 제품의 기본적인 개념 및 특성을 살핀 후 그에 따른 관련 이론들을 검토하였으며 이 를 바탕으로 소비자돌의 태도에 영향을 미칠 수 있는 변수들을 도출, 가상의 컨버전스 제품 들을 대상으로 소비자 서베이를 통한 실증분석 을 시도하였다. 


\section{II. 이론적 배경}

\section{1 컨버전스 제품의 특성}

컨버전스 제품이란 앞서 언급한 바와 같이 산 업과 기술, 콘텐츠 등이 융합되고 있는 큰 흐름 속에서 기술을 매개로 서로 다른 독특한 특성 을 지녔던 제품의 기능들이 하나의 방향으로 수렴된 제품이라 할 수 있다(Covell 2000). 기 업의 입장에서는 이러한 컨버전스 제품을 통해 잠재적인 수익의 증가는 물론, 비용감소 선택 사양의 증가를 꾀할 수 있으며 소비자들 역시 다양한 욕구의 충족을 가져올 수 있는 장점이 있는 것이다(Wind and Mohajan 2002).

이러한 컨버전스 제품은 일찍이 다제품 상호 작용(multiproduct interaction)에서도 그 특성 을 살펴볼 수 있는데, 다제품 상호작용이란 신 제품이 성숙한 기존제품을 기술적으로 대체하 거나 또는 보완하는 등 폭 넓고 다양한 관계를 의미하는 것이고, 이러한 다제품 상호작용의 경우 소비자들의 입장에서는 다양한 혜택(benefit) 과 비용(cost)의 묵음제품(bundle product)으로 인 식할 수 있는데, 특히 그 가운데에서 그러한 다 제품간의 상호작용이 단일 복합제품(all-in-one product)의 형태로 제공되는 것이 컨버전스 제 품을 의미한다고 볼 수 있다(Bayus. Kim, and Shocker 2000).

이러한 다제품 상호작용의 특성을 바탕으로 컨버전스 제품의 특성을 정리해 보면 다음과
같다." 첫째, 컨버전스 제품의 경우 구성 제품 간의 상호작용이 개별적이 아닌 단일 복합제품의 형태에서 발생한다. 즉 묶음제품의 유형 중 묵 음제품을 구성한 각각의 제품을 따로 구매할 수 없으며 단지 단일 제품만을 구매할 수 있는 순수 묶음제품(pure bundling)인 셈이다(Venkatesh and Mahajan 1993). 둘째, 이러한 순수 묶음형 태로 발생하는 컨버전스 제품의 경우 각각의 별개 제품과도 경쟁관계에 놓일 수 있다는 특 성이 있다. 셋째, 단일 복합제품 형태에서 발생 하는 양자간의 상호작용은 대체성 또는 보완성 등 폭넓고 다양한 관계를 바탕으로 할 수 있다 (Bayus, Kim, and Shocker 2000). 넷째, 전통 적인 묶음제품의 경우 주로 가격에 소구하고 있으나 하이테크 기술을 기반으로 하고 있는 컨버전스 제품의 경우 기술 또는 편의성 등에 소구하고 있는 차이가 있다. 결론적으로 컨버전 스 제품이란 구성제품간의 다양한 관계를 바탕 으로 한 하이테크 단일 복합제품으로 정의내릴 수 있다.

\section{2 하이테크 제품 관련 소비자 연구}
2.2.1 혁신제품에 대한 소비자 태도 연구: 혁신저항이론을 중심으로

앞서 언급한 바와 같이 최근 들어 컨버전스 제품의 출시가 가속화되고 있는 것은 기술의 발전이 있었기 때문에 가능한 일이었다. 고도 의 기술력으로 인해 하나의 제품 안에서 많은

1) 컨버전스 제품에 대해 다시 한번 그 특성을 종합적으로 정리할 수 있는 계기를 마련해주신 익명의 심사위원께 감사를 드립니다. 
기능들을 처리할 수 있게 된 것이다. 첨단 기 술제품인 만큼 소비자들의 입장에서 볼 때 컨 버전스 제품은 기존에 없었던 새로운 제품, 즉 혁신제품으로 받아들여질 가능성이 크다. 따라 서 혁신제품이 시장에서 소비자들에게 어떻게 받아들여지는가에 대한 고찰은 컨버전스 제품 의 성공을 위해 매우 중요한 사안이라 할 것 이다.

Moore(1991)에 의하면 첨단기술이 집약된 신 제품이 시장에서 성공하느냐 실패하느냐는 바 로 캐즘(chasm)을 극복하느냐, 극복하지 못하 느냐에 달려있다고 했다. 캐즘이란 첨단 기술제 품이 처음 시장에 소개될 때 진보적 성향의 소 비자들에게는 환영을 받지만 주류시장의 소비 자들에게 파급되지 못한 채 곧 시장에서 소멸 되어 가는 현상을 말한다. 일종의 혁신에 대한 저항(resistance to innovation)인 셈이다. 물론 이러한 혁신저항은 혁신 수용의 반대 개념이 아니라 수용 및 확산으로 이어지는 과정으로 볼 수 있다(Ram 1987). 대개의 신제품은 그것 에 대한 소비자들의 저항이 어느 정도 극복된 후에야 보급되기 시작하며(유필화, 이승희 1994), 특히 기술제품의 경우 그러한 경향은 더욱 크 다는 것이다.

기존의 소비재 및 산업재 연구에서도 이러한 혁신저항과 관련된 연구들이 많이 진행되어 왔 다(유필화, 이승희 1994; 장대련, 조성도 2002; Ram 1987, 1989: Sheth 1981). 주로 혁신저항 에 영향을 미치는 요인들에 대한 개념적 - 실증 적인 연구들이다. 예를 들어 Sheth(1981)는 혁 신저항에 영향을 미치는 변수로 기존의 습관과 지각된 위험을 제시하였으며, 이는 이후 Ram (1989)에 의해 실증적으로 입증되기도 하였다.
한편 $\operatorname{Ram}(1987)$ 은 개념적인 혁신저항모델의 제시를 통해 혁신 특성변수와 소비자 특성변수, 그리고 의사소통 변수(또는 보급경로 톡성변 수)가 소비자들의 혁신저항에 영향을 미친다고 주장하였다. 여기서 혁신 특성변수들은 혁신적 인 신제품의 제품특성을 말하는 것으로서, 소비 자들이 각각의 특성에 대해 어떻게 지각하느냐 에 따라 반응이 달라질 수 있는 소비자 종속적 인 변수 군과 모든 소비자들로부터 저항반응이 동일하게 나타날 수 있는 소비자 독립적인 변 수 군으로 양분될 수 있다(유필화, 이승희 1994; Ram 1987).

국내에서는 유펼화, 이승희(1994)가 $\operatorname{Ram}(1987)$ 의 혁신저항모델을 수정·보완하여 혁신 특성 변수, 즉 (1) 상대적 이점(relative advantage), (2) 적합성(compatibility), (3) 지각된 위험(perceived risk), (4) 복잡성(complexity), (5) 더 좋은 제품 출현에 대한 기대, (6) 시용 가능성(trialability), (7) 용도의 다양성(diversity), (8) 실질적 효용 (realization), (9) 의사소통성(communicability) 및 소비자 특성변수(즉, 심리적 변수군과 인구 통계학적 변수군) 등을 중심으로 실증연구를 시도하였다. $\operatorname{Ram}(1987)$ 이 제시하였던 의사소 통 변수들은 혁신저항을 유발하는 요인이라기 보다는 혁신확산시의 장애요인으로 보고 제외 하였으며, 혁신 특성변수로 제시한 9개 변수들 중 처음 5 가지 변수들은 앞서 설명한 소비자 종속적인 변수에 해당하는 것들이고 나머지 4 가지 변수들은 소비자 독립적인 변수들에 해당 한다. 실증분석 결과 혁신 특성변수의 일부(지 각된 위험, 적합성, 다양성, 의사소통성)와 소비 자 특성변수의 일부(개성, 신념 등)가 혁신저항 에 영향을 미치는 것으로 나타났다. 한편 이러 
한 혁신저항 연구에서 주로 다루어지고 있는 혁신 특성변수들은 Rogers(1983)의 혁신확산 모델을 통해서도 혁신적인 신제품이 확산을 통 해 성공하기 위한 주요 요인들로 다루어지고 있기도 하다.

\subsection{2 기술에 대한 소비자 태도 연구}

최근 Mick and Fournier(1998)는 기술제품을 사용하는 소비자들을 대상으로 한 심층면접을 통해 소비자들이 기술을 받아들이는 데 있어서 8가지의 역설적인 반응(paradoxes of technology) 을 보이는 것을 밝혀내기도 하였다. 연구결과에 의하면 기술은 소비자들이 새로운 것의 출현을 통해 혜택을 누림과 동시에 곧 낡은 것을 경험 하게 하는 등, 다양한 역설적인 양상을 제공함 으로써. 결국 근심과 스트레스를 가져다주고 이 러한 부정적인 경험은 소비자들로 하여금 기술 제품의 특성과 성능에 대한 정보를 회피하거나. 특정 기술제품의 구매롤 줄이는 거부하며, 구매 시기를 지연하는 등 반대적인 행동을 유발하게 된다고 한다.

한편 실무적인 측면에서 미국의 인터넷 조사 및 연구기관인 Forrester Research 사는 신기술 및 전자상거래, 인터넷 비즈니스 전략 등을 개 발하는 과정에서 기존의 인구통계학적 변수나 심리적인 변수 등의 한계점을 인식하고 새로운 소비자들의 이해의 도구로서 기술의 수용정도 와 관련한 테크노그래픽스(technographics)를 개발하여 제시하였으며(Bernoff, Morrisette, and Clemmer 1998), 이를 바탕으로 소비자들을 신 기술에 대한 태도가 높은 낙관자와 낮은 비관 자로 구분하기도 하였다.
2.3 제품 결합에 대한 소비자 태도 연구: 묵음제품을 중심으로

그 동안 묶음제품과 관련된 연구들에서도 어 떤 개별제품들이 함께 묶여야 소비자로부터 좋 은 반응을 얻을 수 있는지에 대해 많은 연구들이 선행되었다. 이러한 연구결과들을 살펴볼 때 중 요한 요인으로 대두되고 있는 것이 묶음제품을 구성하고 있는 제품들간 보완성(complementarity) 의 개넘이다. 즉 구성된 제품간에 서로 보완성 이 없는 묶음 제품에 비해 보완성이 큰 묶음제 품이 소비자에게 더 좋은 반응을 얻는다는 것 이다(Estelami 1999; Gaeth, Levin, Chakraborty, and Levin 1991; Guiltinan 1987; Harlam, Krishna. Lehmann, and Mela 1995).

한편 제품간의 지각된 일치성을 의미하는 보 완성의 개념은 여러 의미를 내포할 수 있다. Aaker and Keller(1990)는 보완성을 '두 제품이 함께 사용되었을 때 더 좋은 효과를 볼 수 있 는 것'으로 정의하고 있으며, 대체성을 '같은 욕 구를 충족시키기 위해서 한 제품이 다른 제품 을 대신할 수 있는 것으로 구별하고 정의하고 있다. 그러나 Park et al.(1991)은 제품간의 보 완적인 관계를 제품의 특징, 제품 이용상황, 제 품 기능의 유사성으로 폭넓게 바라보고 있다. Oxenfeldt(1966) 역시 구성제품의 가치를 높여 서 전체 이미지를 높일 수 있는 것을 보완적인 관계로 바라보고 있다. Varadarajan(1986) 역시 완전보완성, 부분보완성, 이용시간 및 이용상황 의 보완성. 이용과정의 보완성 등 다양한 의미 로 보완성을 폭넓게 정의내리고 있다.

이와 같이 제품간의 지각된 일치성을 모색하 는 연구이외도 묶음제품에 대한 소비자들의 가 
치평가 과정을 규명하려는 연구들에서도 중요 한 요인을 살펴 볼 수 있는데, 묶음제품을 구성 하고 있는 제품들에 대해 소비자들이 느끼는 상대적인 중요도(relative importance)가 그것이 다. Lola(1982)는 묶음제품에 대한 소비자들의 평가모델에서 묶음제품에 대한 평가기준과 조 정(anchoring and adjustment)의 개념을 제시 하고 있는데, 이에 따르면 소비자들은 묶음제품 을 평가할 때 탐색(scanning)과 평가기준 설정 (anchoring), 그리고 평가기준에 의한 조정 (adjustment) 과정을 순차적으로 밝게 된다고 한다. 다시 말해, 소비자들은 탐색단계에서 묶 음제품을 구성하고 있는 개별 제품을 파악하고. 평가기준 설정 단계에서 가장 중요하다고 판단 되는 제품을 선정함으로써 평가를 시작하며, 마 지막 평가기준에 의한 조정단계에서 중요하다 고 판단된 제품을 기준으로 전체 묶음제품에 대한 평가가 조정된다는 것이다. 그리고 이러한 평가모델은 실험연구를 통해서 입증되기도 하 였다(Yadav 1994). 이처럼 묶음제품을 구성하고 있는 제품들간의 중요도의 차이는 구매의도에 도 영향을 주고 있는 것으로 나타났는데(Harlam, Krishna, Lehmann, and Mela 1995), 소비자들 의 구매의도는 TV와 VCR과 같이 중요도가 비슷한 개별제품으로 구성된 묶음 제품이 그렇 지 않은 묶음제품에 비해 더 높다는 것이다.

\section{III. 연구모형}

앞서 살펴본바와 같이 컨버전스 제품이란 구 성제품간의 다양한 관계를 바탕으로 한 하이테
크 단일 복합제품으로 정의내릴 수 있다. 본 연 구는 컨버전스 제품의 특성과 그에 따른 소비 자들의 태도와의 관계에만 초점을 두고 있다. 즉 컨버전스 제품의 어떤 특성들이 소비자들의 태도와 구매의사에 영향을 미칠 수 있는가에 대한 탐색적인 연구가 목적인 것이다.

본 연구모형을 설정하기 위해 컨버전스 제품 의 정의와 소비자들의 가치에 주목하였다. 즉 컨버전스 제품이란 둘 이상의 구성제품간 관계 가 고려되는 하이테크 복합제품이라는 점과, 다 제품 상호작용의 경우 소비자들의 입장에서는 다양한 혜택(benefit)과 비용-(cost)을 함께 인 식할 수 있듯이. 컨버전스 제품 역시 소비자들 은 혜택과 비용의 상쇄를 통한 가치를 기본으 로 태도와 구매의사가 결정될 수 있다는 점이 다(Bayus, Kim, and Shocker 2000). 본 연구모 형의 도출과정은 다음과 같다.

첫째, 컨버전스 제품이 가지고 있는 혁신적인 신제품의 특성요인 중 소비자들의 태도에 영향 을 미칠 수 있는 혁신특성 변수들을 고려하였 다. 이를 위해 앞서 살펴본 혁신저항에 영항을 미치는 혁신특성 변수들을 대상으로 본 연구모 형에 적합한 변수들을 선별하였다. 이 과정에서 특히 가능한 개개인 소비자들의 입장에선 평가 에 주력하기 위해 시용성, 용도의 다양성, 실질 적 효용, 의사소통성과 같은 소비자 독립적인 성격의 혁신특성 변수들은 본 연구모형에서 제 외하였으며 소비자 종속적인 혁신특성 변수만 을 대상으로(유필화, 이승희 1994: $\operatorname{Ram} 1987$ ) 혜택 및 비용관점에서 접근하였다. 또한 소비자 종속적인 혁신특성 변수듈 가운데 적합성은 제 품이 사용자들의 이전 경험이나 가치관, 습관 등에 일관성이 있는 정도를 의미하는 것으로 
(Aassel 1998), 이는 지각된 위험 가운데 심리 적 또는 사회적 위험을 반영한 것으로 판단되 어 모형의 간명화를 위해 제외하였으며 복잡성 역시 기능적, 시간적인 위험과 연관된다는 판단 으로 제외하였다. 따라서 최종적으로 혁신제품 의 특성을 반영한 변수들 가운데에서는 혜택 관점에서는 상대적 이점이 그리고 비용관점에 서는 지각된 위험, 그리고 더 좋은 제품에 대한 출현기대가 컨버전스 제품에 대한 소비자들의 태도 및 구매의사에 영향을 줄 수 있는 혁신특 성 변수로서 본 연구모형에 포합되었다.

둘째, 이러한 혁신제품 특성변수들은 컨버전 스 제품이 지닌 하이테크 성격을 반영할 수 는 있으나 복합제품을 구성하고 있는 두 제품간의 관계를 반영하지 못하고 있는 약점이 있다. 따 라서 본 연구에서는 혁신특성 변수들을 보완하 기 위해 앞서 살펴본 묶음제품에 대한 태도연 구에서 중요하게 고려된 구성제품간의 지각된 일치성과 구성제품간의 상대적인 중요도를 구
성특성 변수로서 연구모형에 포함시켰다. 구성 제품간의 지각된 일치성이 크다는 것은 곧 소 비자들의 혜택을 의미하는 것이고, 반대로 구성 제품간의 상대적인 중요도의 차이가 크다는 것 은 비용관점인 것이다.

셋째, 비록 본 연구가 컨버전스 제품의 특성 과 소비자들의 태도에만 주목하고 있지만 하이 테크 제품의 경우 소비자들의 신기술에 대한 태도가 제품의 구매에 큰 영향을 미치고 있는 관 계로 앞서 설명한 기술수용정도를 의마하는 테크 노그래픽스라는 개인차 변수(Bernoff, Morrisette, and Clemmer 1998)를 연구모형에 포함시켜 살 펴보았다. 본 연구의 모형의 도출과정은 〈그림 3-1>과 같다.

한편 본 연구모형에서는 기존의 혁신저항과 관련된 실증연구에서 입증되지 못했던 변수들 (예: 상대적 이점, 더 좋은 제품출현에 대한 기 대)을 포함하고 있는데, 이는 본 연구모형에서 다루고 있는 종속변수와 관련이 있다. 본 연구

〈그림 3-1〉 연구모형 도출과정

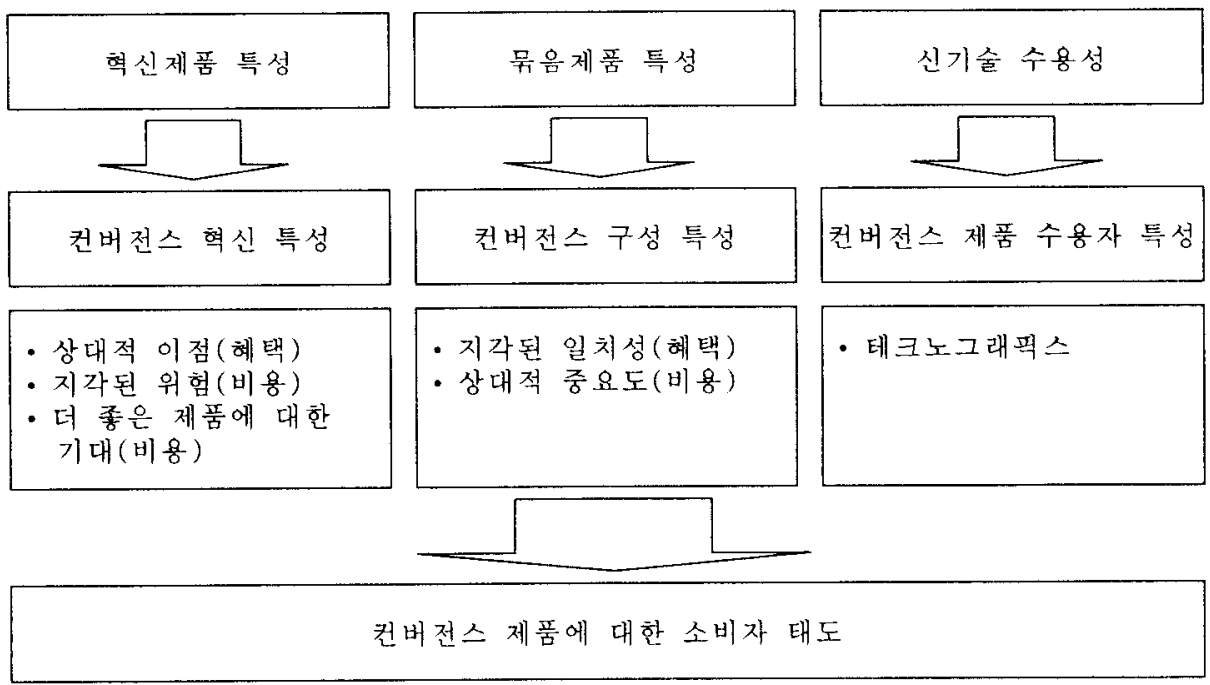


모형에서는 기존의 혁신저항 모델에서 종속변 수로 다루어왔던 혁신저항변수 대신에 일반적 인 신제품에 대한 태도와 구매의도를 종속변수 로 다루고 있기 때문이다. 이는 본 연구가 컨버 전스 제품 상황에서 소비자들의 혁신저항에 대 한 연구라기보다는 해당 제품에 대한 소비자들 의 일반적인 반응을 살펴보는 것을 목적으로 하고 있기 때문이다. 이는 기존 혁신저항 연구 (예: 유필화, 이승희 1994)에서도 언급되었듯 이, 특정 영향요인들의 경우 이들 요인들에 대 해 불만족하더라도 일반적으로 소비자들은 현 실 속에 완벽한 제품이란 어렵다고 생각하거나 관대하게 생각하는 경향으로 인해 신제품에 대 한 강한 저항의 반응과 상태까지는 이르지 않 게 될 수 있다는 것을 반영한 결과이기도 하다.

\section{N. 연구방법}

본 연구는 실제 컨버전스 제품의 사용경험자 를 대상으로 한 평가라기보다는 가상의 컨버전 스 제품들에 대한 소비자 평가를 통해 이루어 졌다. 이는 아직까지 다양한 종류의 컨버전스 제품에 대한 실제 경험 있는 소비자들을 고르 게 찾아 평가하기는 힘들 것이라는 예상에서였 다. 따라서 먼저 기술관련 전자제품군을 대상으 로 사전조사를 통해 14 개 가상의 컨버전스 제 품을 선정하였으며, 본 조사를 통해 이들 컨버 전스 제품들에 대한 소비자태도 및 구매의도. 그리고 영향요인들과의 관계를 살펴보는 방식 으로 진행되었다.

\section{1 사전조사}

사전조사의 목적은 평가대상인 가상의 컨버전 스 제품을 선정하는 데 있다. 일단 본 연구에서 는 컨버전스 제품을 구성하는 개별제품의 수를 2 개로 한정하였으며 가능한 휴대용 제품군과 비휴대용 제품군을 고르게 반영하려 하였다. 이 를 위해 휴대용 제품군에서는 핸드폰과 $\mathrm{PDA}$ 를, 비휴대용 제품군에서는 TV와 스캐너를 선 택하였다. 이는 평가대상인 학생층을 고려한 선 택이기도 하다. 이 4 가지 제품 각각에 대해 다 른 제품들을 조합시키는 방식으로 다양한 가상 의 컨버전스 제품들을 구성하였으며 100 명의 대학생들을 대상으로 지각된 일치성 정도를 측 정한 후 최종 평가대상 제품들을 선정하였다. 가능한 한 계열 내(예: 핸드폰과 조합되는 컨 버전스 제품들)의 제품간 지각된 일치성 정도 가 차이가 나도록 최종 제품을 선정하였으며 너무 낮은 일치성을 보인 제품들은 현실성을 고려하여 제외하였다. 이러한 방식은 복합제품 또는 브랜드확장에 대한 기존의 연구방식에서도 찾아볼 수 있다(Aaker and Keller 1990: Yadav 1994).

이러한 기준을 충족시켜주는 최종 대상으로는 비 휴대용 제품군에서는 TV와 스캐너를 기준 으로 구성되는 6 개의 컨버전스 제품이 선정되 었으며 휴대용 제품군에서는 핸드폰과 $\mathrm{PDA}$ 를 기준으로 구성되는 8개의 컨버전스 제품이 선 정되었다. 대상제품들은 〈표 4-1〉과 같다.

사전조사를 통해, 한 제품을 기준으로 두 제 품간의 지각된 일치성정도가 고르게 분포될 수 있는 제품의 쌍을 선택하다보니 대상 제품들이 과거 또는 현재 시중에 나와 있는 제품들도 일 
〈표 4-1〉 연구대상 제품

\begin{tabular}{|c|c|c|}
\hline 기준 제품 & 컨버전스 제품 & 지각된 일치성* \\
\hline \multirow{3}{*}{ 스캐너 } & 스캐너 + 컴퓨터 & $5.51(0.88)$ \\
\hline & 스캐너 + 프린터 & $5.23(1.22)$ \\
\hline & 스캐너 + 복사기 & $4.71(1.77)$ \\
\hline \multirow{3}{*}{ TV } & $\mathrm{TV}+\mathrm{VCR}$ & $5.45(0.92)$ \\
\hline & $\mathrm{TV}+\mathrm{DVD}$ & $5.17(1.01)$ \\
\hline & $\mathrm{TV}+\mathrm{CDP}$ & $3.78(1.45)$ \\
\hline \multirow{4}{*}{ 핸드폰 } & 핸드폰 + PDA & $5.07(0.85)$ \\
\hline & 핸드폰 + 디지털 녹음기 & $4.75(0.91)$ \\
\hline & 핸드폰 $+\mathrm{MP3}$ 플레이어 & $4.36(1.28)$ \\
\hline & 핸드폰 + TV & $4.11(1.51)$ \\
\hline \multirow{4}{*}{ PDA } & $\mathrm{PDA}+\mathrm{MP3}$ 플레이어 & $5.04(1.25)$ \\
\hline & $\mathrm{PDA}+\mathrm{E}-$ Book 단말기 & $5.00(1.18)$ \\
\hline & $\mathrm{PDA}+$ 디지털 녹음기 & $4.88(1.22)$ \\
\hline & $\mathrm{PDA}+\mathrm{TV}$ & $4.33(1.13)$ \\
\hline
\end{tabular}

* 7점척도 기준, ( )은 표준편차

부 포함되었는데, 개인적인 경험에 따른 차이를 최대한 배제하기 위해 본 조사에서는 해당 컨 버전스 제품에 대한 사용경험 또는 구매경험을 측정하였으며, 이러한 경험자는 대상에서 제외 하였다.

\section{2 변수의 조작적 정의 및 측정}

\subsection{1 독립변수의 정의 및 측정}

\subsubsection{1 혁신특성 변수}

\section{(1) 상대적 이점}

상대적인 이점이란 혁신제품이 소비자에 의해 교체될 이전 제품보다 좋거나 또는 매력적인 정도롤 의미하는 것으로, 경제적인 이점은 물론
편리성, 시간이나 노력의 절감 등을 의미한다 (Rogers 1983; Schiffman and Kanuk 1991). 본 연구에서는 컨버전스 제품이 각각 따로 제 품을 구입하는 경우에 비해 저렴할 것이라는 '지각된 가격'과, Davis(1989)가 제시한 지각된 편리성 개념을 반영하여, 각 개별제품을 따로 이용하는 것보다 컨버전스 제품을 이용하는 것 이 더 편리한지를 평가하는 '지각된 편리성'을 7 점 리커트 척도 $(1=$ "전혀 그렇지 않다", $7=$ "매우 그렇다"; 이후 측정항목 중 상대적인 중 요도를 제외하고는 모두 7점 리커트 척도 사 용)를 통해 측정하였다.

(2) 지각된 위험

마케팅에서 소비자들의 위험지각은 다양한 차 원으로 측정되어져 왔는데(Jacoby and Kaplan 
1972: Roselius 1971), 본 연구에서도 이러한 다 양한 유형을 반영하여 품질에 대한 근심인 성 능 위험(performance risk), 구매할 제품이 개 인의 이미지와 맞지 않을 가능성인 심리적 위 험(psychological risk), 구매 행위가 다른 사람 에 의해 어떻게 평가될지에 대한 사회적 위험 (social risk), 제품 고장 시 수선이나 대체를 위 한 시간 소요가 클 것에 대한 시간적 위험(time risk), 마지막으로 금전적 손실이 발생할 경우 에 대한 재정적 위험(financial risk) 등을 측정 하였다. 평가대상 제품들의 특성을 고려하여 신 체적인 위험(physical risk)은 제외하였다.

(3) 더 좋은 제품출현에 대한 기대 하이테크 산업의 경우 새로운 기술과 제품의 개발이 급속하게 이루어지는 경향이 강하다. 그 리고 이러한 기술변화에 따른 신제품의 도입, 그리고 이에 대한 소비자들의 기대와 걱정은 소비자들로 하여금 이전 제품의 구매에 대한 후회와 새로운 제품구입에 대한 망설임 등을 유발하는 중요한 원인이 되기도 한다(Dhebar 1996). 기대는 곧 걱정을 동반하게 된다. 또한 앞서 살펴보았듯이 소비자들은 새로운 기술에 대해 누릴 수 있는 혜택과 동시에 곧 낡은 것 을 경험하게 되는 역설적인 상황에 직면하개 된다(Mick and Fournier 1998). 따라서 본 연 구에서는 더 좋은 제품출현에 대한 기대의 개 념을 구매한 후, "더 좋은 제품이 나올 것 같아 걱정된다", "컨버전스 제품을 구성하고 있는 각 각의 제품이 빠르게 변하기 때문에 구매하기가 망설여진다" 등과 같이 미래에 대한 소비자들 의 근심의 개념으로 조작화하여 측정하였다.

\subsubsection{2 구성특성 변수}

(1) 지각된 일치성

앞서 설명한바와 같이 소비자들의 지각된 일 치성을 구성하는 '보완성'의 개념은 그 정도에 따라 매우 다양하게 정의될 수 있다(Aaker and Keller 1990; Oxenfeldt 1966: Park, Milberg, and Lawson 1991: Varadarajan 1986). 순수하 게 두 제품이 함께 사용될 수 있는 경우를 강 조할 수도 있지만(Aaker and Keller 1990), 제 품의 이용상황이나 기능이 유사한 경우에도 서 로 보완의 관계에 있는 것으로 해석될 수 있 는 것이며(Park, Milberg, and Lawson 1991; Varadarajan 1986), 이러한 폭넓은 보완의 관계 는 결국 최종적으로는 구성제품의 가치를 높여 서 전체적인 이미지를 높일 수 있는 것이다 (Oxenfeldt 1966).

본 연구에서는 Varadarajan(1986)이 제시한 이용상황에서의 보완성의 개넘을 컨버전스 제 품을 구성하고 있는 각각의 제품들이 이용상황 에서 함께 사용할 가능성의 정도로 조작화 하 여 측정하였으며. Aaker and $\operatorname{Keller}(1990)$ 가 이 용한 보완성의 개념으로 두 제품이 함께 사용 되었을 때 더 좋은 효과를 볼 수 있다는 정도 를 측정하였다. 한 제품이 다른 제품을 대신한 다는 개념인 '대체성'의 개념 역시 지각된 일차 성에 포함될 수 있으나(Aaker and Keller 1990), 이러한 대체관계 역시 기능의 유사성 또는 이 용상황의 유사성을 전제로 하는 것이며, 이는 폭넓은 의미에서 소비자들에게는 보완의 개념 으로 해석될 수 있기 때문에 이용상황에서의 보완성의 개념으로 대신하였다. 예를 들어 유사 한 기능을 발휘하는 $\mathrm{DVD}$ 와 $\mathrm{VCR}$ 의 경우 기술 
적으로는 대체관계로 설명할 수 있지만, 유사한 사용상황에서 유사한 기능을 발휘한다는 점, 그 리고 기술의 발전과정에서 서로의 부족한 점을 채워줄 수 있다는 점, 이러한 과정을 통해 특히 최종적으로 함께 있을 경우 구성제품의 가치를 높일 수 있다는 측면에서 소비자들에게는 보완 의 관계로도 받아들여질 수 있는 것이다.

(2) 상대적 중요도

컨버전스 제품을 구성하고 있는 제품들간의 상대적인 중요도는 '지각된 중요도'와 '이용량의 차이'를 측정하였으며 모두 100 점을 배분하는 방식으로 측정하였다(Yadav 1994).

\subsubsection{3 제품 수용자 특성변수}

기술의 수용정도와 관련한 테크노그래픽스는 Forrester Research 사에서 개발한 신기술에 대 한 태도변수들 중 기술에 대한 호의도. 기술의 중요성 인식. 새로운 기술제품을 알기 위해 시 간을 보내기를 좋아하는 정도를 선택적으로 사 용하였다.

\section{2 .2 종속변수의 측정}

본 연구에 있어서 종속변수는 컨버전스 제품 에 대한 소비자의 태도와 구매의도이다. 이중 태도는 응답자가 인지하는 컨버전스 제품에 대 한 주관적인 생각을 재미, 흥미, 호감으로 평가 하였으며. 구매의도는 단일 문항으로 측정하였다.

\section{3 자료수집}

본 조사의 자료수집은 오프라인과 온라인을
통해 편의표본추출(convenience sampling) 방 식으로 이루어졌다. 가능한 다양한 계층의 표본 을 얻기 위함이었으며, 오프라인의 경우 대학교 학생들을 중심으로 이루어졌으며 이를 보완하 기 위해 온라인상의 직장인 동호회 사이트에 배너광고를 통해 설문을 실시하였다. 본 설문에 는 총 452 명이 응답하였으며 이 가운데 설문이 불성실한 경우 등을 제외하고 최종분석에는 422 명이 포함되었다. 응답자는 14 개 가상의 컨버전 스 제품들 중 한 가지에 대해서만 응답하도록 하였으며, 각 제품별로 30 명 내외의 응답자가 구성되었다.

\section{V. 연구결과}

\section{1 응답자 특성}

조사결과 처음의 목적과는 달리 온라인 조사 의 참여가 부족한 관계로 대부분 학생표본으로 구성되었다. 남성이 $53.2 \%$, 여성 $46.8 \%$ 를 차지 하였으며 학생이 전체의 $89 \%$ 를 차지하였다.

\section{2 신뢰성 및 타당성 검증}

본 연구에 포함된 독립변수들의 수렴타당성과 판별타당성을 살펴보기 위해 탐색적인 요인분 석과 신뢰성검증을 실시하였다. 요인분석 방법 중 주성분분석(principal component analysis)을 이용하였으며 요인회전은 배리맥스(varimax) 방법으로 실시하였다.

먼저 요인분석결과 혁신특성 변수 가운데 '상 
〈표 5-1〉 독립변수 요인분석 결과

\begin{tabular}{|l|c|c|c|c|c|c|}
\hline & 요인 1 & 요인 2 & 요인 3 & 요인 4 & 요인 5 & 요인 6 \\
\hline 더 좋은 제품 출현1 & .779 & .070 & .070 & -.082 & .091 & .121 \\
시간적 위험 & .775 & -.121 & .065 & .098 & .089 & -.095 \\
더 좋은 제품 출현2 & .752 & .179 & -.034 & -0.07 & -.039 & .205 \\
금전적 위험 & .697 & -.030 & -.159 & .035 & -.020 & -.158 \\
성능위험 & .595 & -.025 & .159 & .304 & -.012 & -.200 \\
\hline 테크노그래픽스1 & .030 & .907 & .087 & -.042 & .061 & -.011 \\
테크노그래픽스2 & .050 & .869 & .109 & -.104 & .097 & .031 \\
테크노그래픽스3 & -.026 & .841 & .068 & .065 & -.067 & .060 \\
\hline 지각된 일치성1 & -.068 & .107 & .895 & -.052 & -.116 & .102 \\
지각된 일치성2 & .025 & .111 & .888 & .003 & -.038 & .043 \\
\hline 사회적 위험 & .112 & .015 & -.012 & .899 & -.030 & -.065 \\
심리적 위험 & .030 & -.075 & -.079 & .884 & -.073 & -.081 \\
\hline 상대적 중요도1 & .006 & .017 & -.009 & -.017 & .889 & .053 \\
상대적 중요도2 & .017 & .056 & -.126 & -.019 & .874 & -.060 \\
\hline 상대적 이점1(가격) & .010 & -.001 & .050 & .038 & -.011 & .877 \\
상대적 이점2(편리) & -.115 & .120 & .354 & -.128 & .015 & .533 \\
\hline
\end{tabular}

대적 이점'과 구성특성 변수인 '지각된 일치성' 과 '상대적 중요도', 수용자 특성변수인 테크노 그래픽스는 독립적인 요인으로 확인되었으나, 혁신특성 변수 중 '지각된 위험' 가운데 시간적. 금전적. 성능 위험의 경우 '더 좋은 제품출현에 대한 기대'와 수렴되는 형태로 나타났으며, 심 리적, 사회적 위험의 경우 독립적인 요인으로 나타났다. 요인분석결과는 〈汪 5-1〉과 같다.

이처럼 지각된 위험요소들간의 상관관계와 별 도의 차원으로의 판별현상은 기존 연구들에서 도 확인되었으며(Chaudhuri 2000: Stone and Gronhaug 1993), 본 연구에서 사용한 '더 좋은 제품출현에 대한 기대'의 개념 역시 그 조작화 의 내용에 비추어 판단해 보면 시간적. 금전적, 성능위험과 관련이 있어 보인다.

따라서 본 연구가 탐색적인 성격의 연구임을
고려하여 요인분석의 결과대로 심리적, 사회적 위험을 '감성적 위험(emotional risk)'으로, 다른 위험항목들과 더 좋은 제품출현에 대한 기대를 '기능적 위험(functional risk)'으로 명명하여 새 로운 독립변수로 고려하였다.

한편 각 요인들의 내적 일관성을 살펴보기 위 해 신뢰성계수(cronbach's alpha)를 살펴본 결 과는 〈표 5-2〉와 같다. 독립변수 중 다른 요인 들과 종속변수 중 소비자 태도와 관련된 3개의 문항에서는 모두 높은 내적 일관성이 확보되었 으나 독립된 요인으로 확인되었던 '상대적 이 점의 두 문항이 기준치(Nunnally 1970)에 미달 되는 값을 나타냄에 따라 '상대적 이점'을 구성 하는 '지각된 가격'과 '지각된 편리성'은 별도의 독립변수로 최종 연구모형에 포함시켰다. 
〈표 5-2〉 독립변수 및 종속변수 신뢰성

\begin{tabular}{|c|c|c|}
\hline 구성개넘 & 문항수 & 신뢰성 계수 \\
\hline 기능적 위험 & 5 & 0.7699 \\
\hline 감성적 위험 & 2 & 0.7931 \\
\hline 상대적 이점 & 2 & $0.3947^{*}$ \\
\hline 지각된 일치성 & 2 & 0.8360 \\
\hline 상대적 중요도 & 2 & 0.7239 \\
\hline 테크노그래팍스 & 3 & 0.8520 \\
\hline 소비자 태도(종속변수) & 3 & 0.9248 \\
\hline
\end{tabular}

* 상대적 이점은 지각된 가격과 편리성으로 독립적인 변수로 처리함

\section{3 분석결과}

본 연구에서는 컨버전스 제품에 대한 소비자 들의 평가와 그 영향요인들간의 관계를 살펴보 기 위해 '소비자태도' 및 '구매의도'를 종속변수 로 하여 다중회귀분석을 실시하였다. 회귀분석 결과는 〈표 5-3〉과 같다. 회귀분석에서는 척도 의 이질성을 고려하여 비표준화 계수(beta)를 살폈다.

먼저 소비자 태도 및 구매의도를 대상으로 한 회귀모형은 각각 유의한 것으로 판명되었다(소 비자 태도: $R^{2}=.299 . F=24.546, p<.001$ : 구 매의도: $R^{2}=286, F=22.926, p(.001)$. 각 독 립변수 별 영항력 정도를 살펴본 결과. 소비자 들이 컨버전스 제품의 사용에서 느끼는 '기능적 위험'의 경우 소비자 태도에는 유의적인 영향을 미치지 않았으나 $(\beta=.026, p=.543)$, 구매의도에 는 부(-)의 유의적인 영향을 미치는 것으로 나 타났다 $(\beta=-.122, p$ (.001), 반면 '감성적 위험' 의 경우는 소비자 태도에는 부(-)의 유의적인 영향을 미쳤으나 $(\beta=-.073, p<.1)$, 구매의도에 는 유의적인 영향을 미치지 않는 것으로 나타
났다 $(\beta=-.037, p=.395)$.

컨버전스 제품을 구성하고 있는 두 제품간의 '상대적 중요도'의 경우 상대적인 중요도차이가 클수록 소비자들의 태도 및 구매의도 모두에 부정적인 영향을 미치는 것으로 나타났으며(소 비자 태도: $\beta=-219, p<.001$; 구매의도: $\beta$ $=-207, p$ (.001). 두 제품간의 '지각된 일치 성 정도는 모두 긍정적인 영향을 미치는 것으 로 나타났다(소비자 태도: $\beta=.339, p<.001$ : 구매의도: $\beta=.296 . p$ (.001).

컨버전스 제품의 상대적 이점을 반영한 '지각 된 편리성 역시 소비자 태도 및 구매의도에 모 두 긍정적인 효과가 있는 것으로 나타났으나 (소비자 태도: $\beta=.201, p$ <.001: 구매의도: $\beta$ $=.164, p$ (.001), "지각된 가격'은 유의적인 영 향을 미치지 않는 것으로 나타났다(소비자 태도: $\beta=.008, p=.847$ : 구매의도: $\beta=.036, p=.406$ ).

기술에 대한 태도를 반영한 개인변수인 테크 노그래픽스의 경우 기술에 대한 태도가 낙관적 인 사람일수록 컨버전스 제품에 대한 구매의도 가 높은 것으로 나타났다. 단 제품에 대한 태도 에는 유의적안 영향을 미치지 않는 것으로 나 
(1) 종속변수: 소비자 태도 $\left(R^{2}=299\right)$

\begin{tabular}{|l|r|r|c|}
\hline \multicolumn{1}{|c|}{ 독립변수 } & $\beta$ 계수 & $t$-값 & $p$-값 \\
\hline 기능적 위험 & .026 & .609 & .543 \\
감성적 위험 & -.073 & -1.698 & .090 \\
지각된 가격 & .008 & .193 & .847 \\
지각된 편리성 & .201 & 4.266 & .000 \\
지각된 일치성 & .339 & 7.325 & .000 \\
상대적 중요도 & -.219 & -5.162 & .000 \\
테크노그래픽스 & .035 & .800 & .424 \\
\hline
\end{tabular}

(2) 종속변수: 구매의도 $\left(R^{2}=.286\right)$

\begin{tabular}{|l|c|c|c|}
\hline \multicolumn{1}{|c|}{ 독립변수 } & $\beta$ 계수 & $t$-값 & $p$-값 \\
\hline 기능적 위험 & -.122 & -2.816 & .005 \\
감성적 위험 & -.037 & -.851 & .395 \\
지각된 가격 & .036 & .831 & .406 \\
지각된 편리성 & .164 & 3.437 & .001 \\
지각된 일치성 & .296 & 6.327 & .000 \\
상대적 중요도 & -.207 & -4.822 & .000 \\
테크노그래픽스 & .120 & 2.754 & .006 \\
\hline
\end{tabular}

타났다(소비자 태도: $\beta=.035, p=.424$; 구매의 도: $\beta=.120, p(.01)$.

\section{VI. 결론 및 토의}

\section{1 연구결과 요약}

본 연구는 디지털 시대의 총아로 각광받고 있 는 컨버전스 제품에 대한 소비자들의 평가와 그에 미치는 영향요인들의 영향력정도를 실증 분석하고 있다. 연구결과를 요약해보면 다음과 같다.
첫째, 컨버전스 제품에 대한 소비자들의 태도 와 구매의도는 해당 컨버전스 제품을 구성하고 있는 각 제품들간의 관계에 따라 가장 큰 영향 을 받는 것으로 나타났다. 즉, 각각의 제품들간 의 상대적인 중요도(즉. 소비자들이 지각하는 중요도의 차이 및 이용량의 차이 정도)의 차이 가 발생할수록 컨버전스 제품에 대한 소비자들 의 태도와 구매의도는 부정적으로 나타난 반면, 각각의 구성제품들간 소비자들이 지각하는 일치 성의 정도가 클수록 태도 및 구매의도는 긍정적 으로 나타났다. 이러한 결과들은 비록 하이테크 제품은 아니지만 기존의 묶음제품에 대한 소비 자 연구의 결과들과도 일맥상통하는 것이다.

둘째. 기존의 혁신저항의 연구에서는 실증되 
지 못했던 상대적인 이점의 경우, 컨버전스 제 품의 상황에서는 각각의 제품을 사용할 때에 비해 느낄 수 있는 지각된 편리성은 컨버전스 제품의 태도와 구매의도에 긍정적인 영향을 미 치는 것으로 나타났다. 단. 지각된 가격과 같은 컨버전스 제품의 경제적 이점은 영향력이 없는 것으로 나타났다.

셋째, 기존의 혁신저항의 연구와 마찬가지로 지각된 위험은 컨버전스 제품의 태도와 구매의 도에 영향을 미치는 것으로 나타났다. 단 본 연 구에서는 컨버전스 제품의 태도에는 감성적 위 험만이. 그리고 구매의도에는 기능적 위험만이 영향을 미치는 것으로 나타났다.

넷째, 기술에 대한 태도를 반영한 소비자 특 성변수인 테크노그래픽스 역시 컨버전스 제품 의 구매의도에 영항을 미치는 것으로 나타났다. 즉 기술에 대해 낙관적인 성향을 지닌 소비자 일수록 이러한 컨버전스 제품의 구매의도가 높 다는 것을 의미한다. 단 본 연구에서는 소비자 태도에는 큰 차이가 없는 것으로 나타났다.

\section{2 연구결과의 시사점}

본 연구를 통해 살펴볼 수 있는 학문적. 관리 적 시사점은 다음과 같다. 본 연구는 무엇보다 도 최근 들어 실제 마케팅 현장에서 매우 중요 하게 부각되고 있음에도 불구하고 상대적으로 연구가 부족하였던 컨버전스 제품을 대상으로 기존의 혁신저항 및 묶음제품과 관련된 소비자 연구들 바탕으로 컨버전스 제품의 성공요인을 탐색해 보았다는 데 학문적인 의의가 있다고 할 수 있다. 또한 본 연구결과를 통해 실제 컨 버전스 제품의 마케팅 활동에 도움을 줄 수 있
는 몇 가지 시사점을 도출해 볼 수 있다.

첫째, 성공적인 컨버전스 제품이 되기 위해서 는 무엇보다 해당 컨버전스 제품을 구성하게 되는 개별 제품들간의 관계를 잘 설정해야한다 는 것이다. 이는 컨버전스 제품의 경우 각각의 제품들이 이미 시장에 출시되어 있는 상황에서 소비자들은 이에 대해 정말 새로운 혁신적인 제품에서 느낄 수 있는 저항적인 요인들보다는 현실적인 측면에서 각 제품의 구성이 어떠한 효과를 가져다 줄 것인가에 더 민감하게 반응 할 수 있다는 측면을 보여주는 것이라 할 수 있다. 실제 소비자들이 각각의 제품들을 사용하 는 정도가 어느 정도인가? 그에 따라 각각의 제품들을 모두 동등하게 여기는가? 또한 각각 의 제품들에서 소비자들은 일치성을 느낄 수 있는가? 이러한 요인들에 대한 충분한 검토가 매우 중요한 과제라 할 수 있다. Dhebar(2001) 는 기존의 캐즘이론을 바탕으로 다양한 형태의 캐즘과 그에 대한 극복방안을 제시하였는데, 그 가운데 과거와의 단절에서 발생하는 캐즘을 극 복하는 방안으로 급격한 변화 대신 과거제품과 의 연결고리를 제공하라고 충고하고 있다. 최근 국내에서 성공을 거둔 $\mathrm{VCR}$ 과 DVD의 복합제 품 역시 소비자들에게는 사용제품간의 보완가 능성을 통해 급격한 변화에 대한 완충역할을 제공했다는 측면으로도 볼 수 있을 것이다.

둘째. 소비자들이 컨버전스 제품을 통해 얻을 수 있는 상대적인 이점으로는 편리성과 같은 심리적인 측면이 가격과 같은 경제적인 측면에 비해 우월할 수 있다는 가능성이다. 이러한 소 비자들의 반응은 컨버전스 제품을 구매한 후. 한 가지는 거의 사용하지 않는 경우가 발생하 거나 또는 고장 등으로 인한 손실의 가능성들 
이 복합적으로 고려된다면, 단지 구매시점에서 의 절대적인 가격은 이점으로 작용하기 어려울 수 있다는 의미로 해석해 볼 수 있다. 물론 대 개의 컨버전스 제품이 각각의 제품을 구매하는 것에 비해 더 저렴한 것이 사실이고, 본 연구가 실제 구매자들을 대상으로 한 것이 아니므로 이러한 측면은 향후 연구에서 보다 심도 있게 파악해 볼 필요가 있을 것으로 사료된다.

셋째. 컨버전스 제품의 태도와 구매의도에 미 치는 소비자들의 지각된 위험이 다른 양상을 나타낼 수 있다는 것은 해당 마케팅 커뮤니케 이션 활동에 시사점을 줄 수 있다. 실제 구매에 대해서는 시간적 위험, 성능 위헙, 금전적 위험. 더 좋은 제품 출현에 대한 걱정과 같은 요인들 을 완화시켜줄 수 있는 마케팅 커뮤니케이션 활동이 더욱 강조되어야 하는 반면, 대중을 상 대로 한 컨버전스 제품에 대한 호의적인 태도 형성을 위해서는 개인의 심리적. 사회적인 위험 을 감소시켜줄 수 있는 활동이 더 효과적일 수 있다는 것이다. 이는 기술에 대한 평소 성향 (즉, 테크노그래픽스)이 컨버전스 제품의 태도 에는 영향을 미치지 않는 반면 구매의사에는 영항을 미친다는 사실과도 연결 지어 생각해 볼 수 있는테, 즉 장기적인 대중시장의 형성과 단기적인 목표시장의 활동을 잘 구분 지어 접 근해야 한다는 것을 의미한다고 할 수 있다.

\section{3 연구의 한계 및 미래 연구방향}

이와 같은 사항들에도 불구하고 본 연구는 몇 가지 측면에서 한계점을 가지고 있다. 먼저 본 연구는 실제 구매상황이 아닌 가상의 제품군들 을 대상으로 학생표본이 주를 이루어 연구되었
다는 한계점이 있다. 보다 광범위한 표본대상과 실제 구매경헙자를 대상으로 한 연구를 통해 결과의 일반화를 높일 수 있을 것이다. 또한 무 엇보다도 본 연구는 과거 혁신저항 및 묶음제 품의 연구를 바탕으로 몇 가지 영향변수만을 선택적으로 적용한 탐색적 수준에 머물고 있다 는 한계점을 지적할 수 있다. 비록 컨버전스 제 품이 하이테크 제품의 성격과 묶음제품의 성격 을 지녔지만 근본적으로 이러한 성향을 뛰어넘 는 컨버전스 제품만의 특성과 영향요인들에 대 한 심층적인 접근이 필요할 것이다. 이러한 문 제점들은 본 연구결과를 기초로 해서 향후 연 구에서 보다 보완되어야 할 것으로 보인다.

본 연구와 관련하여 향후에서는 몇 가지 확장 된 연구가 가능할 것으로 보인다. 첫째, 기존의 혁신저항이론에 있으나 본 연구에서는 생략된 다른 변수들(예를 들면, 다른 소비자 특성변수. 또는 소비자 독립적인 혁신 특성변수들)을 포 함한 연구모형의 확장을 시도해 볼 수 있을 것 이다. 특히 이러한 연구모형의 확장은 앞서도 지적했듯이 보다 컨버전스 제품만의 특성을 반 영할 수 있는 방향으로 시도되어야 할 것이다. 둘째, 본 연구에서 가장 큰 영향력을 보인 두 제품간의 관계에 초점을 둔 보다 구체적인 연 구가 진행될 수 있을 것이다. 상대적인 이용량 이나 중요도의 정도 및 일치성의 정도를 보다 구체적으로 구분한 실험연구들을 통해 해당 수 준의 영향력을 심도 있게 파악해 볼 수 있을 것이다. 또한 본 연구에서는 2 개의 제품이 합쳐 진 컨버전스 제품만을 대상으로 하였으나 향후 연구에서는 그러한 경우를 늘려 적용해 볼 수 도 있을 것이다.

기술은 끊임없이 변화하고 있으며. 동시에 소 
비자들 역시 점차 다양해지고 복잡해지고 있다. 기술시대의 소비자들 역시 컨버전스의 특성을 지니고 있다고 한다. 때로는 전통적으로 때로는 기술에 심취하는, 마치 신화에 등장하는 '캔타 우어(centaur)', 즉 말의 하반신과 인간의 상반 신을 가진 존재에 비유되기도 한다(Wind and Mahajan 2002). 그만큼 기업들이 상대하기 어 렵고 복잡할 수 있다는 의미이기도 하다. 이러 한 소비자들을 상대로, 컨버전스 제품들이 단순 히 기업관점에서의 생산 효율성의 제고를 위한 수단적인 방편이 아니라. 정말 미래기술을 선도 하고 소비자들에게 보다 큰 효용을 가져다 줄 수 있는 실질적인 신제품의 역할을 수행하기 위해 기업들의 더 많은 노력과 이해가 필요해 보인다.

〈논문 접수일: 2004. 08, 23〉 〈게재 확정일: 2005, 02, 03〉

\section{참고문헌}

나준호(2002). "디지털 컨버전스 시대의 3가지 패러독스". LG주간경제, 690호, 24-28. 매경이코노미(2002), "멀티플레이어가 좋다." 7. 24. (2003), "융합비즈니스가 뜬다." 11.

\section{5. $26-34$}

유필화. 이승희(1994), "신제품수용시 소비자의 혁신저항에 관한 연구: 혁신저항 모형을 중 심으로" 경영학연구, 제23권 제3호, 217-249. 장대련, 조성도(2002), "기술제품 사용자의 조직 내 혁신저항에 영향을 미치는 요인과 지각
된 자기능력의 조절효과에 관한 연구," 소 비자학연구, 제 13 권 제3호, 245-262. 조선일보(2004), "LCD 디스플레이+가전품 '융 합 끝이 없다." 6. 28. D1.

Aaker, David A. and Kevin Lane Keller(1990), "Consumer Evaluations of Brand Extension," Journal of Marketing, 54(January), 27-41. Assael, Henry(1998), Consumer Behavior and Marketing Action, 6th ed., Cincinnati, Ohio: South Western.

Bayus, Barry L., Namwon Kim, and Allan D. Shocker(2000), "Growth Models for Multiproduct Interactions: Current Status and New Directions," in Vijay Mahajan, Eitan Muller, and Yoran Wind (eds.), New Product Diffusion Models, Boston, MA: Kluwer Academic Publishers, 141-163.

Bernoff, Josh, Shelley Morrisette, and Kenneth Clemmer(1998), "Technographics Explained," The Forrester Report.

Covell, Andy(2000). Digital Convergence, Aegis Publishing Group.

Chaudhuri, Arjun(2000). "A Macro Analysis of the Relationship of Product Involvement and Information Search: The Role of Risk." Journal of Marketing Theory and Practice, Winter, 1-14.

Davis, Fred D.(1989), "Perceived Usefulness, Perceived Ease of Use, and User Acceptance of Information Technology." MIS Quarterly, September, 319-340.

Dhebar. Anirudh(1996), "Speeding High-Tech Producers, Meet the Balking Consumer." 
Sloan Management Review, 37(Winter), $37-54$

(2001) "Six Chasms in Need of Crossing," Sloan Management Review, Spring. 95-99.

Estelami. Hooman(1999), "Consumer Savings in Complementary Product Bundles," Journal of Marketing Theory and Practice, 7 (Summer), 107-114.

Gaeth. Gary J., Irwin P. Levin, Goutam Chakraborty, and Aron M. Levin(1991), "Consumer Evaluations of Multi-Product Bundles: An Information Integration Analysis," Marketing Letters, 2(January), 47-58. Guiltinan, Joseph P.(1987), "The Price Bundling of Services: A Normative Framework," Journal of Marketing, 51(April), 74-85.

Hanson. Ward(2000), Principles of Internet Marketing, Cincinnati, Ohio: South-Western College Publishing.

Harlam, Bari A., Aradhna Krishna, Donald R. Lehmann, and Carl Mela(1995). "The Impact of Bundle Type, Price Framing and Familiarity on Evaluation of the Bundle," Journal of Business Research, 33(1), 57-66.

Jacoby, Jacob and Leon B. Kaplan(1972), "The Components of Perceived Risk," in M. Venkatesan (ed.) Proceedings of the Third Annual Conference of the Association for Consumer Research. College Park. MD: Association for Consumer Research. 382-393. Lola. Lopes L(1982), "Toward a Procedural
Theory of Judgment," Working Paper 17. Wisconsin Human Processing Program, Department of Psychology, University of Wisconsin, Madison.

Mick. David Glen and Susan Fournier(1998). "Paradoxes of Technology: Consumer Cognizance. Emotions, and Coping Strategies," Journal of Consumer Research, 25(September), 123-143.

Moore. Geoffrey A.(1991), Crossing the Chasm New York: Harper Business.

Nunnally, Jum C.(1978), Psychometric Theory, New York: McGraw-Hill.

Park. C. Whan, Sandra Milberg, and Robert Lawson(1991), "Brand Extension Decision: Product Level Sililarity and Brand Concept Consistency," Journal of Consumer Research. 18(September), 161-173.

Ram. S.(1987), "A Model of Innovation Resistance," in Melanie Wallendorf and Paul Anderson (eds.), Advances in Consumer Research, 14, Provo. UT: Association for Consumer Research, 208-212.

(1989). “Successful Innovation Using Strategies to Reduce Consumer Resistance: An Empirical Test," Joumal of Product Innovation Management, 6, 20-34. Ries. Al and Laura Ries(1999). The 11 Immutable Laws of Internet Branding, Harper Information.

Roselius, T.(1971), "Consumer Rankings of Risk Reduction Methods," Journal of Marketing, 35, 56-61. 
Rogers, Everett M.(1983), Diffusion of Innovation, 3rd ed. New York: Free Press.

Sheth, Jagdish N.(1981). "Psychology of Innovation Resistance: The Less Developed Concept (LDC) in Diffusion Research," in J. Sheth (ed.) Research in Marketing, 4. JAI Press, pp. 273-282.

Schiffman, L. G. and L. L. Kanuk(1991), Consumer Behavior, 4th ed., New Jersey: Prentice-Hall.

Stone, Robert N. and Kjell Grönhaug(1993). "Perceived Risk: Further Considerations for the Marketing Discipline." European Journal of Marketing, 27(3), 39-50.
Varadarajan, P. Rajan(1986), "Horizontal Cooperative Sales Promotion: A Framework for Classification and Additional Perspectives," Journal of Marketing. 50(April), 61-73. Venkatesh R. and Vijav Mahajan(1993), "A Probabilistic Approach to Pricing a Bundle of Product or Service." Journal of Consumer Research. 20(November), 494-508.

Wind. Yoram and Vijay Mahajan(2002), "Convergence Marketing," Journal of Interactive Marketing, 16(2), 64-79.

Yadav, Manjit S.(1994), "How Buyers Evaluate Product Bundles: A Model of Anchoring and Adjustment," Journal of Consumer Research, 21(September), 342-353. 


\title{
Consumer Evaluations of Convergence Products
}

\author{
Hae-Ryong Kim* \\ Shin-Myung Hong** \\ Moonkyu Lee*
}

\begin{abstract}
Convergence products, which perform multiple functions, are gaining popularity in the marketplace these days. Unfortunately, however, little research to date has been conducted as to how consumers evaluate such products. The present research, based on the existing literature regarding the innovation resistance and product bundling, examines the factors influencing consumer responses to convergence products. The results of the study reveal that consumer evaluations and purchase intentions are affected by consumer perceptions of risk (emotional and functional), convenience, product complementarity and relative advantage as well as consumer individual differences measured by technographics. Implications of the results for marketers and future research are discussed.
\end{abstract}

Keywords: convergence products, innovation resistance, perceived risk

* Assistant Professor of Marketing. Department of Business Administration, Konkuk University

** Graduate student, School of Business. Yonsei University

*** Professor of Marketing, School of Business. Yonsei University

The authors thank Min Young Choi for her assistance in collecting data 